Article

\title{
AT-MSCs Antifibrotic Activity is Improved by Eugenol through Modulation of TGF- $\beta /$ Smad Signaling Pathway in Rats
}

\author{
Moustafa Fathy ${ }^{1,2}{ }^{\mathbb{D}}$, Motonori Okabe ${ }^{1}$, Heba M. Saad Eldien ${ }^{3,4}$ and Toshiko Yoshida ${ }^{1, *}$ \\ 1 Department of Regenerative Medicine, Graduate School of Medicine and Pharmaceutical Sciences, \\ University of Toyama, Toyama 930-0194, Japan; moustafa_fathyy@yahoo.com (M.F.); \\ okabe@med.u-toyama.ac.jp (M.O.) \\ 2 Department of Biochemistry, Faculty of Pharmacy, Minia University, Minia 61519, Egypt \\ 3 Department of Anatomy, College of Medicine, Jouf University, Jouf 74311, Saudi Arabia; \\ hebasaadeldien2015@yahoo.com \\ 4 Department of Histology and Cell Biology, Faculty of Medicine, Assiut University, Assiut 71515, Egypt \\ * Correspondence: yosida24@med.u-toyama.ac.jp; Tel.: +81-76-434-7211
}

Received: 5 December 2019; Accepted: 14 January 2020; Published: 15 January 2020

\begin{abstract}
For hepatic failure, stem cell transplantation has been chosen as an alternative therapy, especially for mesenchymal stem cells (MSCs). The aim of this study was to investigate the effect of eugenol (EUG) on the in vivo antifibrotic activity of adipose tissue-derived MSCs (AT-MSCs) and the underlying mechanism. After characterization of MSCs, rats were divided into five groups, Group 1 (normal control), Group $2\left(\mathrm{CCl}_{4}\right)$, Group $3\left(\mathrm{CCl}_{4}+\mathrm{AT}-\mathrm{MSC}\right)$, Group $4\left(\mathrm{CCl}_{4}+\mathrm{EUG}\right)$ and Group $5\left(\mathrm{CCl}_{4}\right.$ + AT-MSCs + EUG). Biochemical and histopathological investigations were performed. Furthermore, expression of type 1 collagen, $\alpha$-SMA, TGF- $\beta 1$, Smad 3 and P-Smad 3 was estimated. Compared to the single treatment with AT-MSCs, the combination treatment of the fibrotic rats with AT-MSCs and EUG significantly improved the plasma fibrinogen concentration, IL-10 level and proliferating cell nuclear antigen expression, and also significantly decreased the serum levels of liver enzymes, IL-6, IL- $1 \beta$, TNF- $\alpha$, type III collagen, hyaluronic acid, hydroxyproline and the TGF- $\beta$ growth factor. Furthermore, the combination treatment significantly decreased the hepatic expression of fibrotic markers genes (Type 1 collagen and $\alpha$-SMA) and proteins ( $\alpha$-SMA, TGF- $\beta 1$ and phospho-Smad3) more than the treatment with AT-MSCs alone. We demonstrated that the combination treatment with EUG and AT-MSCs strongly inhibited the advancement of $\mathrm{CCl}_{4}$-induced hepatic fibrosis, compared with AT-MSCs alone, through TGF- $\beta /$ Smad pathway inhibition. This approach is completely novel, so more investigations are necessary to improve our perception of the underlying molecular mechanisms accountable for the effects of EUG on the antifibrotic potential of AT-MSCs.
\end{abstract}

Keywords: AT-MSCs; eugenol; hepatic fibrosis; TGF- $\beta$; Smad3; TNF- $\alpha$; IL-6; $\alpha$-SMA

\section{Introduction}

Recently, for hepatic failure, stem cell transplantation has been chosen as an alternative therapy. Mesenchymal stem cells (MSCs), derived from different organs, have much superiority in regenerative medicine, including multipotent differentiation capacity, their low immunogenic properties and high proliferation rate. Moreover, they have the ability to drift toward the microenvironments of injured sites [1-3]. MSCs also present many other features, like no adverse reactions related to MSCs transplant, and long-term storage without considerable loss of potency [4]. They are immunomodulatory, can directly differentiate to new hepatocytes, have antifibrotic properties, can promote tissue repair and also inhibit hepatic stellate cells activation [5]. 
It was previously reported that bone marrow-derived mesenchymal stem cells (BM-MSCs) are capable of attenuating liver fibrosis [6]. Adipose tissue (AT) is also a good provenance of high proliferative potential MSCs. Clinical investigations using AT-derived MSCs (AT-MSCs) showed enhanced liver function and histology [7-9]. Furthermore, the easy arrival to subcutaneous AT, its uncomplicated isolation methods and the reproducibility to sample this tissue, make AT the most appealing source of MSCs [10].

Hepatic fibrosis is a common outcome of chronic hepatic disorders. During hepatic fibrogenesis, there are raised inflammatory responses and extravagant accumulation of the hepatic extracellular matrix. If inappropriately handled, hepatic fibrosis may proceed to cirrhosis, resulting in patients requiring hepatic transplantation [11,12]. At the present time, hepatic transplantation is the only available therapeutic choice for those patients, but its application is limited by high cost, organ shortage, and the necessity of lifelong immunosuppressive therapy to avoid transplant rejection [13]. Therefore, novel therapeutic strategies are needed to improve care for such patients and for the treatment of hepatic fibrosis.

Recently, we demonstrated the antifibrotic effect of eugenol (EUG), which is the active ingredient of clove essential oil, through its in vivo attenuation of the inducible nitric oxide synthase pathway [14]. Furthermore, we previously maintained and enhanced the differentiation potential of various tissues-derived stem cells [2,3,15-17]. As an extension of the results of previous studies, the present study was designed to inspect the effect of eugenol on the in vivo antifibrotic activity of AT-MSCs and to investigate the underlying mechanisms. Thus, our aim was to examine the effect of eugenol on the intravenously-administered AT-MSCs in improving liver function and decreasing hepatic fibrosis in a carbon tetrachloride $\left(\mathrm{CCl}_{4}\right)$-induced hepatic fibrosis rat model.

\section{Results}

\subsection{Cell Surface Markers Expression}

Cell surface markers expression of AT-MSCs was examined by flow cytometric (FCM) analysis for MSC markers (CD90, CD105 and CD73) and hematopoietic markers (CD34 and CD45). As shown in Figure 1, 75.8\% $\pm 3.5 \%, 82.8 \% \pm 4.9 \%$ and $80.5 \% \pm 5.1 \%$ of the cultured AT-MSCs were expressed CD90, CD105 and CD73, respectively. On the other hand, only $0.5 \% \pm 0.03 \%$ and $4.3 \% \pm 0.3 \%$ of them expressed the hematopoietic markers CD34 and CD45, respectively.

\subsection{Prothrombin Time and Fibrinogen Concentration Assay}

The prothrombin time of normal control rats was $25 \pm 1.0 \mathrm{sec}$. $\mathrm{CCl}_{4}$ significantly $(p<0.001)$ increased the prothrombin time to $42 \pm 2.1 \mathrm{sec}$ while treatment with AT-MSCs, EUG or combination of them significantly decreased it to $27 \pm 0.7,35 \pm 1.1$ or $25 \pm 1.2 \mathrm{sec}$, respectively, when compared to $\mathrm{CCl}_{4}$ group, as shown in Figure 2A.

Also, Figure 2A showed that $\mathrm{CCl}_{4}$ significantly $(p<0.001)$ decreased plasma fibrinogen concentration to $83.9 \pm 1.7 \mathrm{mg} / \mathrm{dL}$ when compared to normal control group $128.9 \pm 2.5 \mathrm{mg} / \mathrm{dL}$. Treatment with AT-MSCs, EUG or both of them significantly increased the fibrinogen concentration to $111.9 \pm 2.4,94.9 \pm 1.8$ or $119.1 \pm 2.1 \mathrm{mg} / \mathrm{dL}$, respectively. There is a significant difference $(p<0.01)$ between rats treated with AD-MSCs + EUG and rats treated with AD-MSCs alone. 

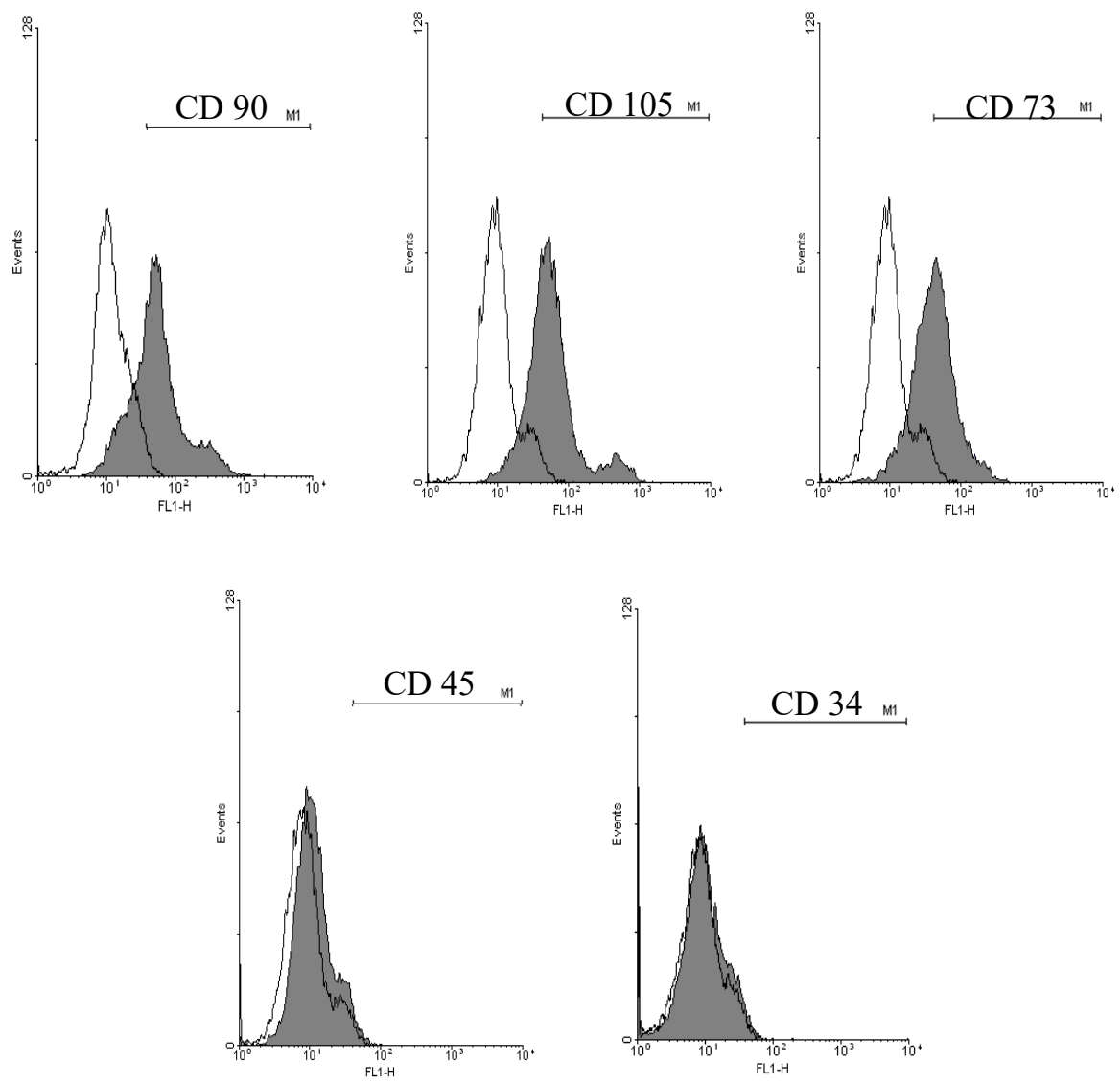

Figure 1. Cell surface markers expression of adipose tissue-derived mesenchymal stem cells (AT-MSCs). Representative histograms of the flow cytometric analysis of the isolated AT-MSCs for the expression of mesenchymal stem cells (MSCs) markers (CD90, CD105 and CD73) and hematopoietic markers (CD34 and CD45). AT-MSCs: Adipose tissue-derived mesenchymal stem cells.

\subsection{Liver Enzymes (ALT and AST) Levels}

Serum levels of ALT and AST were significantly $(p<0.001)$ increased by $\mathrm{CCl}_{4}$ when compared to normal control rats. Both enzymes levels were significantly decreased when rats treated with AT-MSCs, EUG or both of them when compared to $\mathrm{CCl}_{4}$ group. In addition, ALT and AST levels were significantly $\left(p<0.001\right.$ for ALT and $p<0.01$ for AST) decreased in $\mathrm{CCl}_{4}+$ AT-MSCs + EUG group compared to $\mathrm{CCl}_{4}+$ AT-MSCs group (Figure 2B).

\subsection{Serum Inflammatory Cytokines (IL-1 $\beta, T N F-\alpha, I L-6$ and IL-10) Levels}

As shown in Figure 3A, the measured pro-inflammatory cytokines (interleukin-1beta (IL-1 $\beta$ ), tumor necrosis factor-alpha (TNF- $\alpha$ ) and interleukin-6 (IL-6)) were significantly $(p<0.001)$ increased with $\mathrm{CCl}_{4}$ when compared to normal control group. Treatment with AT-MSCs, EUG or both of them significantly decreased these cytokines levels compared to the $\mathrm{CCl}_{4}$ group. Furthermore, their serum levels were significantly decreased in rats of the $\mathrm{CCl}_{4}+$ AT-MSCs + EUG group compared to rats of the $\mathrm{CCl}_{4}+$ AT-MSCs group. On the other hand, the interleukin-10 (IL-10) serum level was significantly $(p<0.01)$ decreased with $\mathrm{CCl}_{4}$, while the treatment with AT-MSCs, EUG or both of them significantly increased its level compared to the $\mathrm{CCl}_{4}$ group, and there is a significant $(p<0.05)$ difference between $\mathrm{CCl}_{4}+$ AT-MSCs and $\mathrm{CCl}_{4}+$ AT-MSCs + EUG groups. 


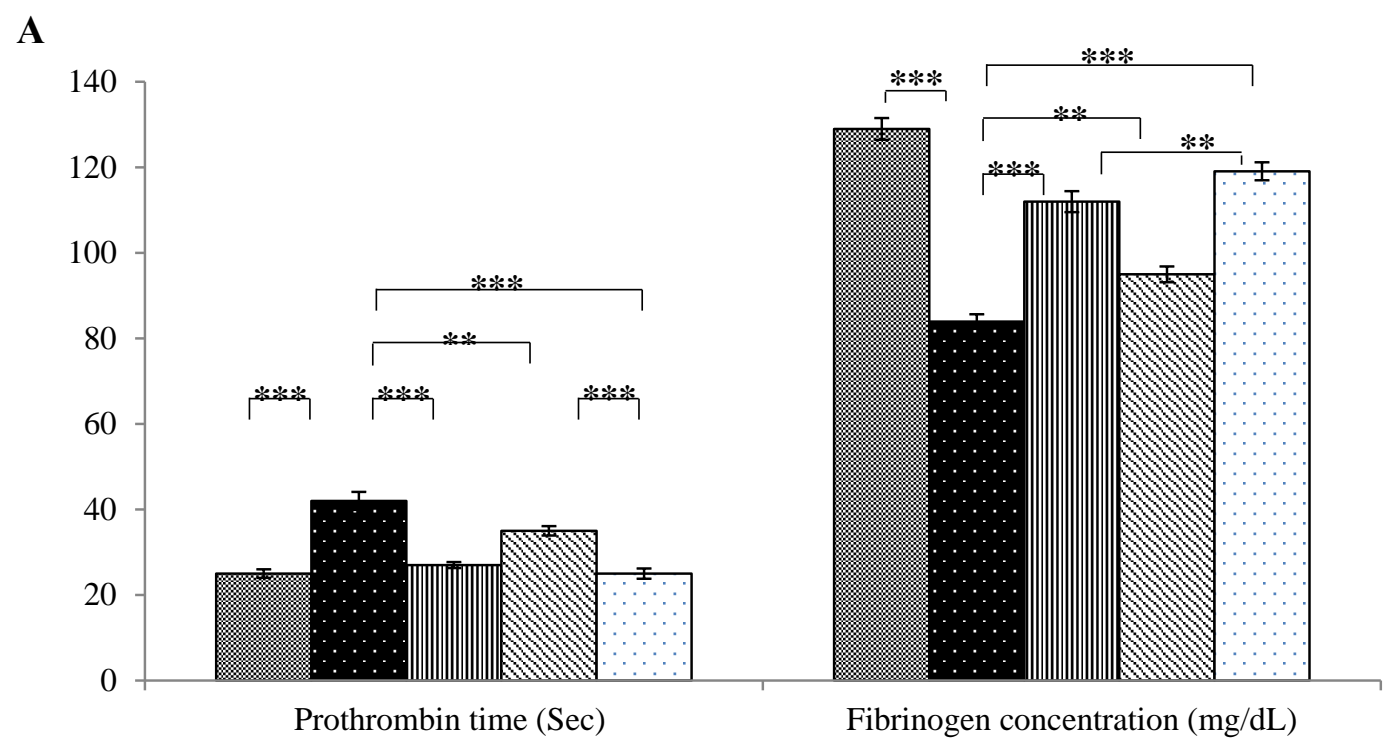

B

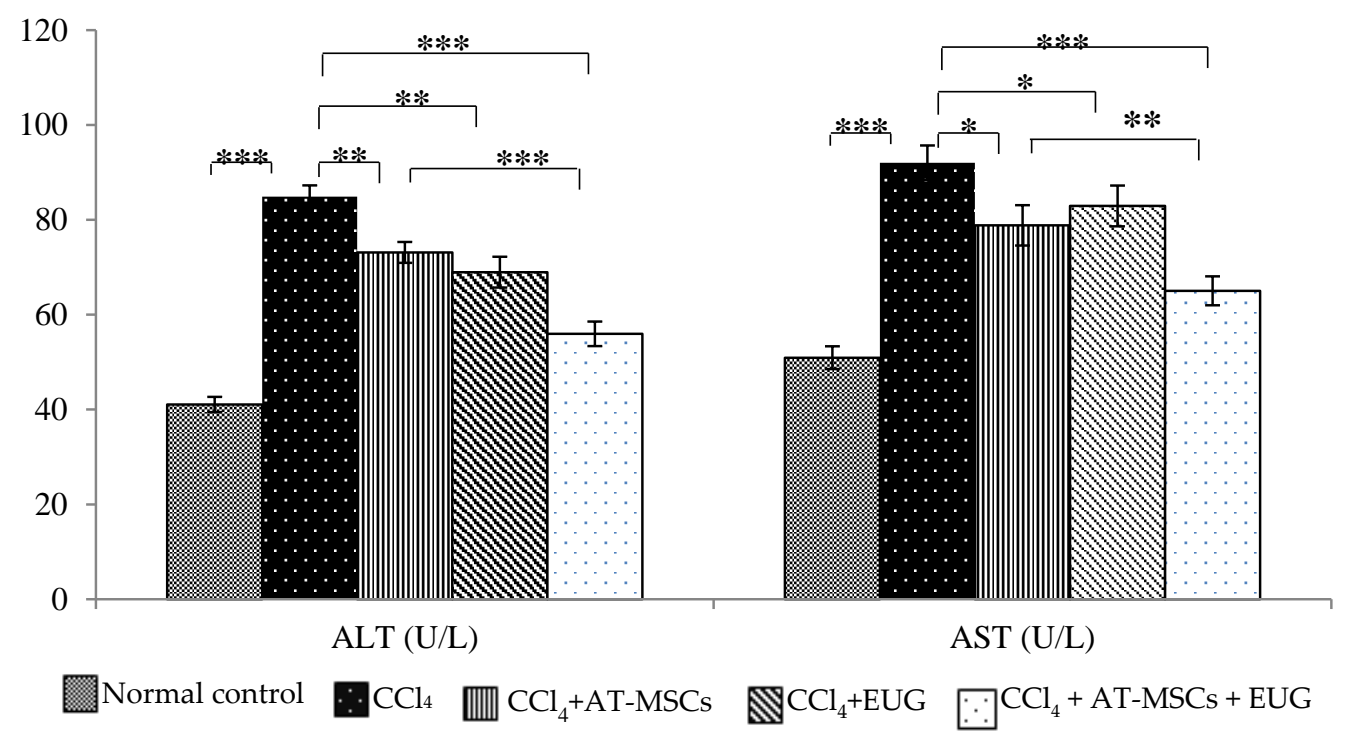

Figure 2. Prothrombin time, fibrinogen concentration and liver enzymes levels. (A) Prothrombin time (sec) and plasma fibrinogen concentration $(\mathrm{mg} / \mathrm{dL}$ ) for the different groups. (B) Serum liver enzymes (ALT and AST) levels (U/L) for the different groups. Bars represent mean \pm standard deviation (SD). Significant difference between groups is analyzed by one-way analysis of variance (ANOVA) test, where: ${ }^{*} ; p<0.05,{ }^{* *} ; p<0.01,{ }^{* * *} ; p<0.001$. AT-MSCs: Adipose tissue-derived mesenchymal stem cells, EUG: Eugenol.

\subsection{Serum Growth Factors (Hepatocyte Growth Factor (HGF) and Transforming Growth Factor-Beta} (TGF- $\beta$ )) Levels

Both factors were significantly ( $p<0.05$ for HGF and $p<0.001$ for TGF- $\beta$ ) increased with $\mathrm{CCl}_{4}$ when compared to the normal control group (Figure 3B). Serum levels of HGF were significantly $(p<0.05)$ increased only in rats treated with AT-MSCs + EUG compared to the $\mathrm{CCl}_{4}$ group, and there is no significant difference between $\mathrm{CCl}_{4}+$ AT-MSCs and $\mathrm{CCl}_{4}+$ AT-MSCs + EUG groups. 
A
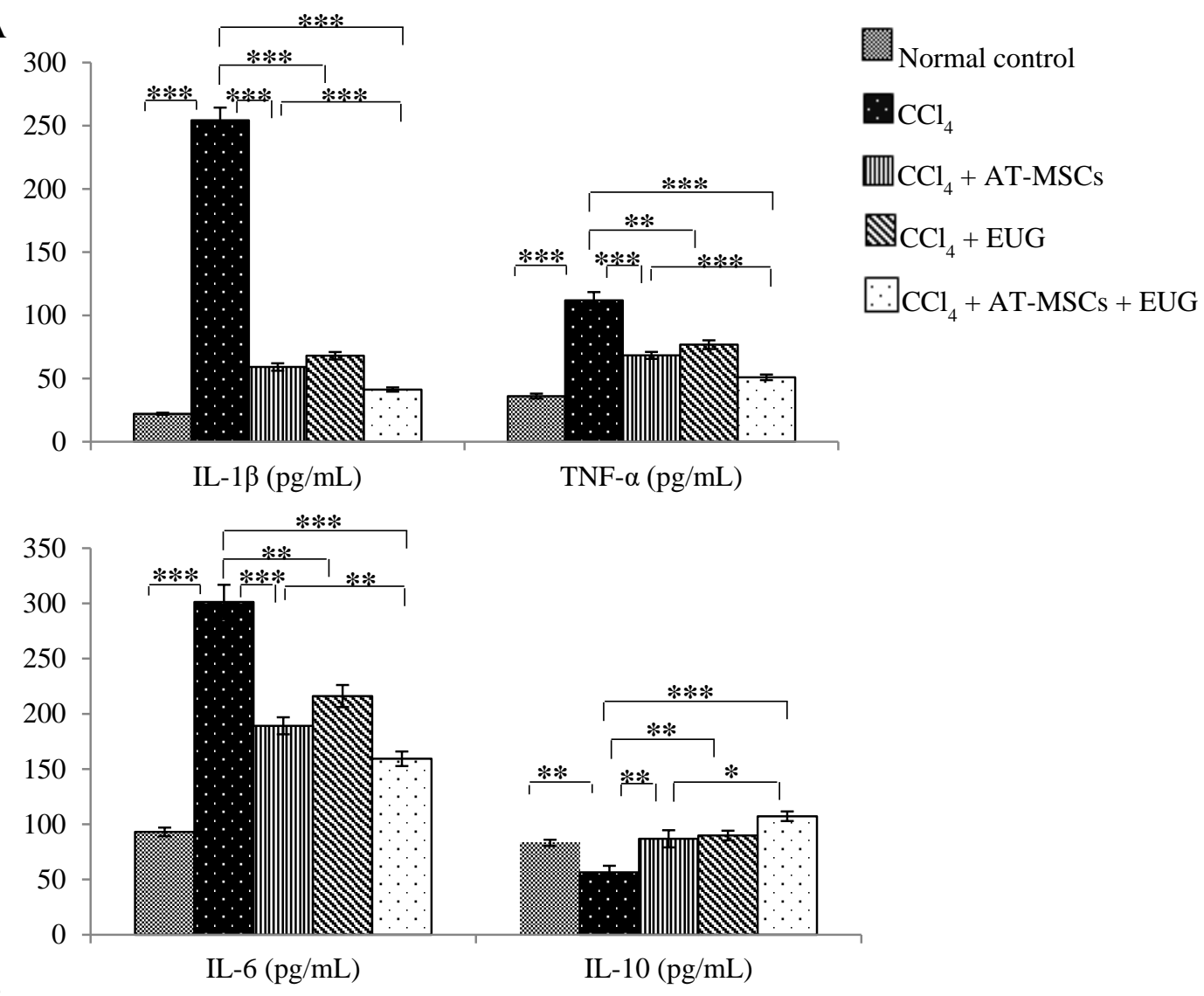

B

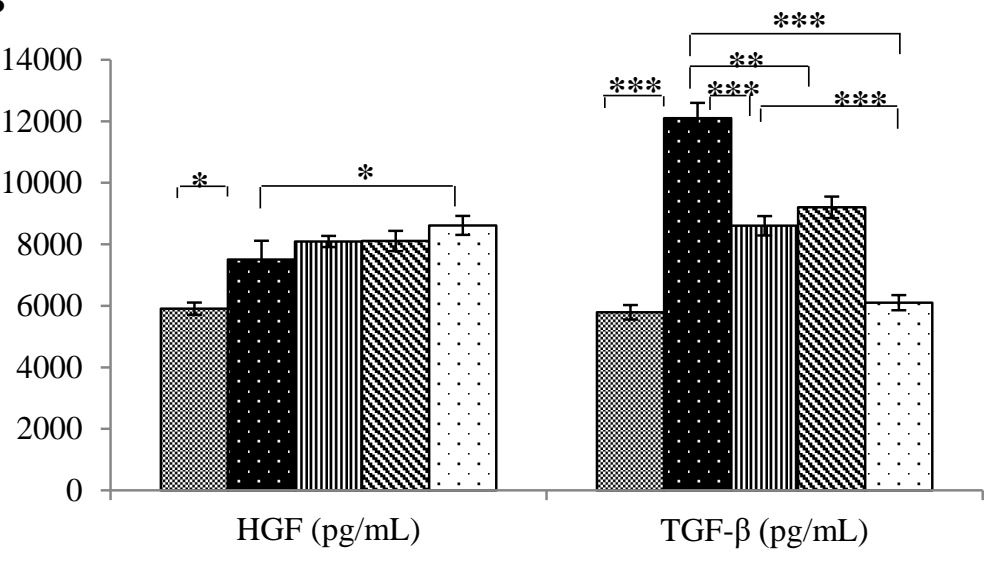

Figure 3. Serum inflammatory cytokines and growth factors levels. (A) Serum cytokines (IL-1 $\beta$, TNF- $\alpha$, IL-6 and IL-10) levels (pg/mL) for the different groups. (B) Serum growth factors (HGF and TGF- $\beta$ ) levels $(\mathrm{pg} / \mathrm{mL})$ for the different groups. Bars represent mean \pm SD. Significant difference between groups is analyzed by one-way ANOVA test, where: ${ }^{*} ; p<0.05, * * ; p<0.01,{ }^{* * *} ; p<0.001$. AT-MSCs: Adipose tissue-derived mesenchymal stem cells, EUG: Eugenol, IL-1 $\beta$ : Interlukin-1 $\beta$; IL-6: Interlukin-6; IL-10: Interlukin-10; TNF- $\alpha$ : Tumor necrosis factor- $\alpha$; HGF: Hepatocyte growth factor; TGF- $\beta$ : transforming growth factor- $\beta$.

TGF- $\beta$ serum levels were significantly decreased in rats treated with AT-MSCs, EUG or both of them compared to $\mathrm{CCl}_{4}$ rats. In addition, there is a significant $(p<0.001)$ difference between $\mathrm{CCl}_{4}+$ AT-MSCs and $\mathrm{CCl}_{4}+$ AT-MSCs + EUG groups. 


\subsection{Levels of Type III Collagen, Hyaluronic Acid and Hepatic Hydroxyproline Content}

Figure 4 showed that, in addition to hepatic hydroxyproline content, serum levels of type III collagen and hyaluronic acid were significantly $(p<0.001)$ increased with $\mathrm{CCl}_{4}$ when compared to the normal control group. Also, they were significantly decreased in rats treated with AT-MSCs, EUG or both of them compared to $\mathrm{CCl}_{4}$ rats. Furthermore, there is a significant difference between $\mathrm{CCl}_{4}$ + AT-MSCs and $\mathrm{CCl}_{4}+$ AT-MSCs + EUG groups ( $p<0.001$ for hepatic hydroxyproline content and $p<0.01$ for type III collagen and hyaluronic acid serum levels).

A

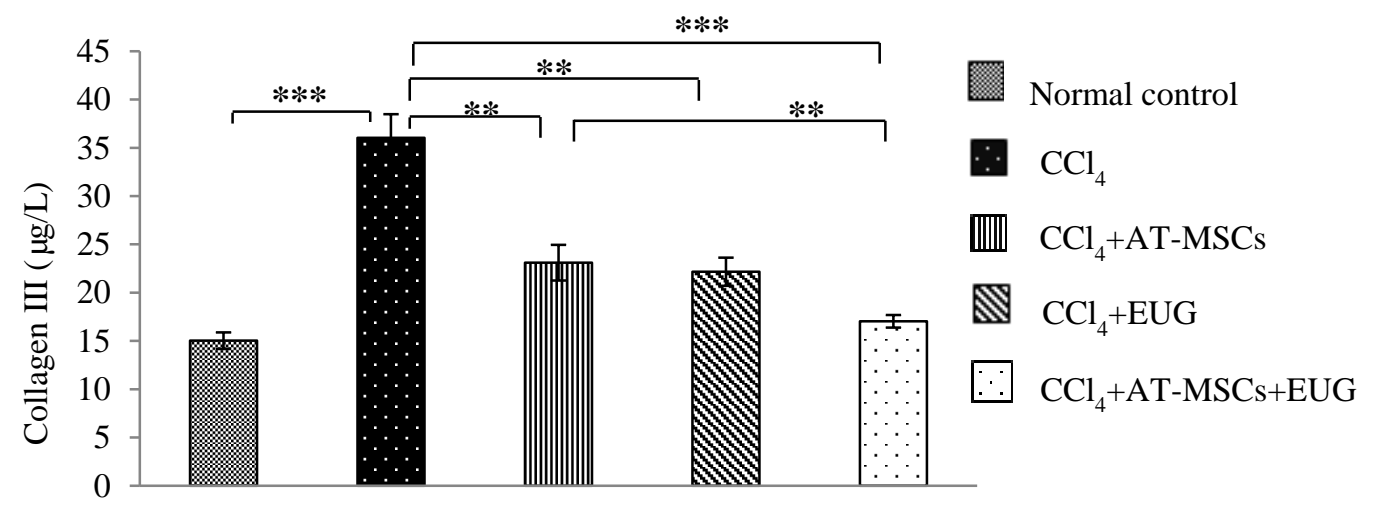

B

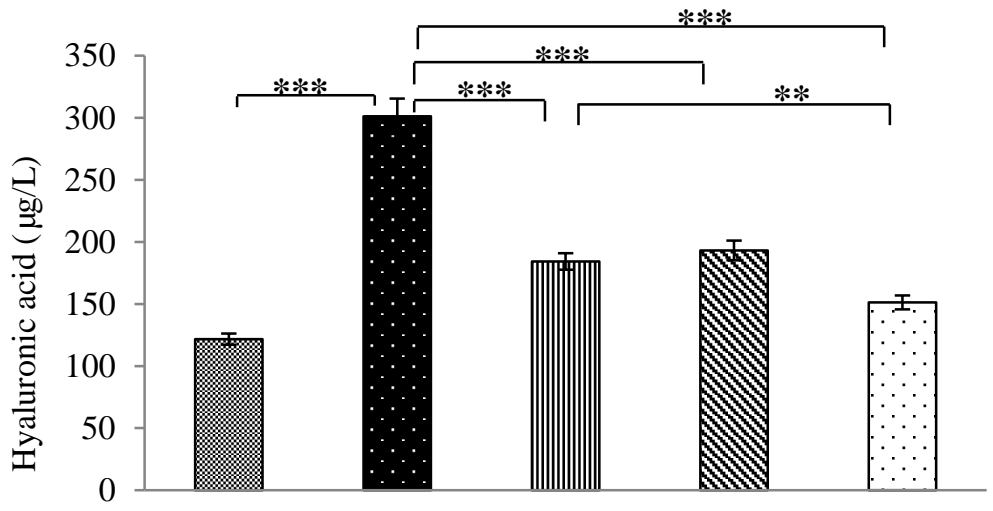

C

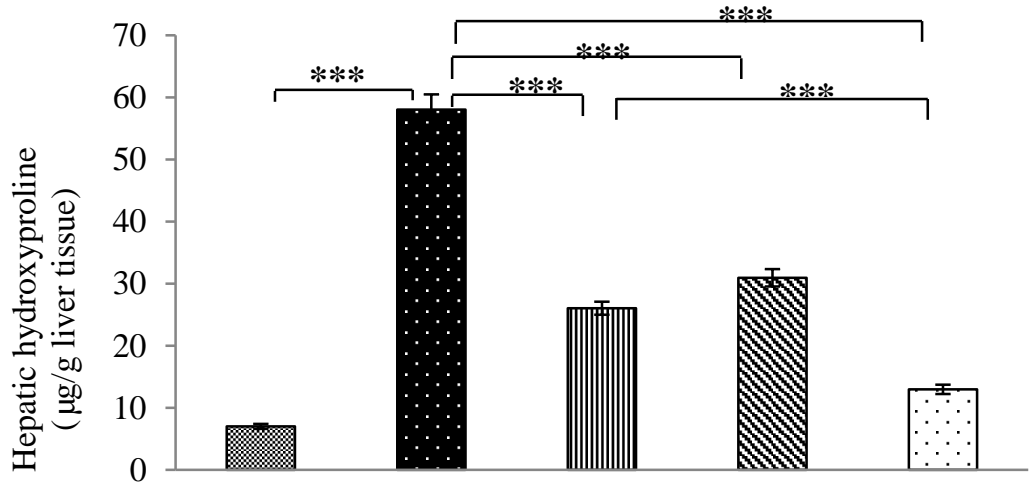

Figure 4. Levels of type III collagen, hyaluronic acid and hepatic hydroxyproline content. Serum levels of (A) collagen III and (B) hyaluronic acid $(\mu \mathrm{g} / \mathrm{L})$ for the different groups. (C) Hepatic hydroxyproline content $(\mu \mathrm{g} / \mathrm{g}$ liver protein) for the different groups. Bars represent mean $\pm \mathrm{SD}$. Significant difference between groups is analyzed by one-way ANOVA test, where: ${ }^{* *} ; p<0.01,{ }^{* * *} ; p<0.001$. AT-MSCs: Adipose tissue-derived mesenchymal stem cells, EUG: Eugenol. 


\subsection{Expression of Proliferating Cell Nuclear Antigen (PCNA)}

Rats receiving $\mathrm{CCl}_{4}$ showed significant $(p<0.01)$ low expression of PCNA compared to normal control rats. Its expression was significantly $(p<0.01$ for rats treated with AT-MSCs or EUG alone, and $p<0.001$ for rats treated with AT-MSCs + EUG) increased when compared to the $\mathrm{CCl}_{4}$ group. There is a significant $(p<0.05)$ difference between $\mathrm{CCl}_{4}+$ AT-MSCs and $\mathrm{CCl}_{4}+$ AT-MSCs + EUG groups (Figure 5).

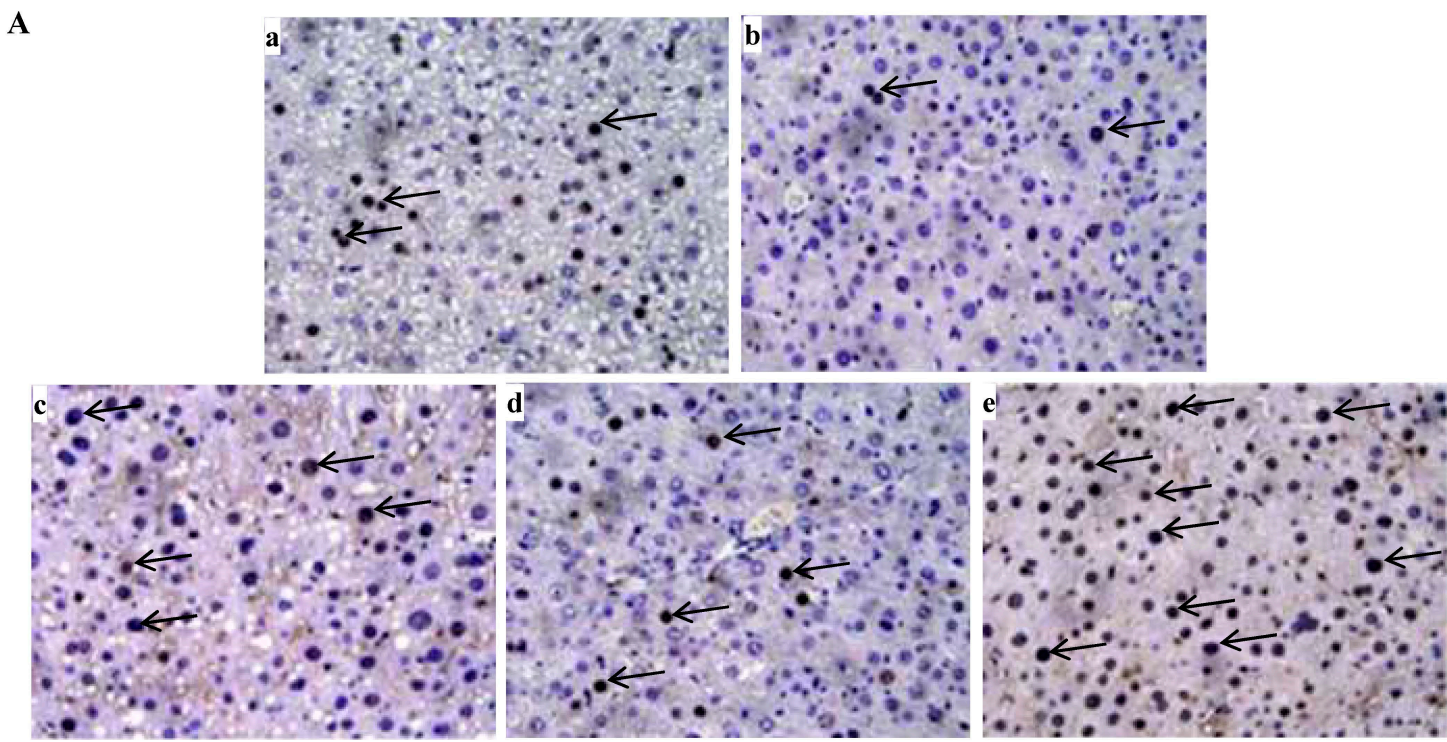

B

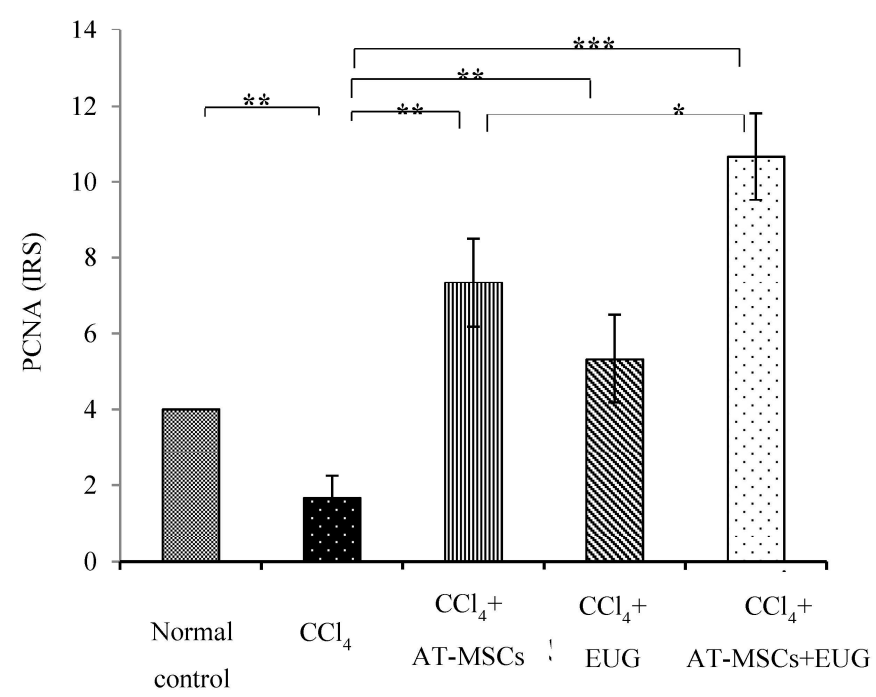

Figure 5. Expression of the proliferating cell nuclear antigen. (A) Representative photos of PCNA staining of hepatic tissues of: (a) normal control rats, (b) fibrotic rats which received $\mathrm{CCl}_{4}$, (c) rats that received $\mathrm{CCl}_{4}+$ AT-MSCs, (d) rats receiving $\mathrm{CCl}_{4}+\mathrm{EUG}$, (e) rats who received $\mathrm{CCl}_{4}+\mathrm{AT}-\mathrm{MSC}$ + EUG, (Magnification: x400). (B) Staining intensities were expressed in immuno-reactive score (IRS). Bars represent mean \pm SD. Significant difference between groups is analyzed by one-way ANOVA test, where: ${ }^{*} ; p<0.05,{ }^{* *} ; p<0.01,{ }^{* * *} ; p<0.001$. AT-MSCs: Adipose tissue-derived mesenchymal stem cells, EUG: Eugenol, PCNA: Proliferating cell nuclear antigen, IRS: Immuno-reactive score.

\subsection{Type 1 Collagen, $\alpha$-Smooth Muscle Actin ( $\alpha$-SMA) and TGF- $\beta 1$ Genes Expression}

Relative to rats of the normal control group and after normalization to glyceraldehyde 3-phosphate dehydrogenase $(G A P D H)$ as a housekeeping gene, Figure 6 showed that $\mathrm{CCl}_{4}$ significantly $(p<0.001)$ 
increased the hepatic mRNA levels of Type 1 collagen, $\alpha$-SMA and TGF- $\beta 1$ genes to become $9.4 \pm 0.4$ folds, $8.3 \pm 0.3$ folds and $5.6 \pm 0.3$ folds, respectively, those of the normal control group. Also, the hepatic expression of the three genes was significantly decreased when rats treated with AT-MSCs, EUG or both of them when compared to the $\mathrm{CCl}_{4}$ group. More interestingly, there is a significant $(p<0.001)$ difference between $\mathrm{CCl}_{4}+$ AT-MSCs and $\mathrm{CCl}_{4}+$ AT-MSCs + EUG groups in the expression of the examined genes.

A

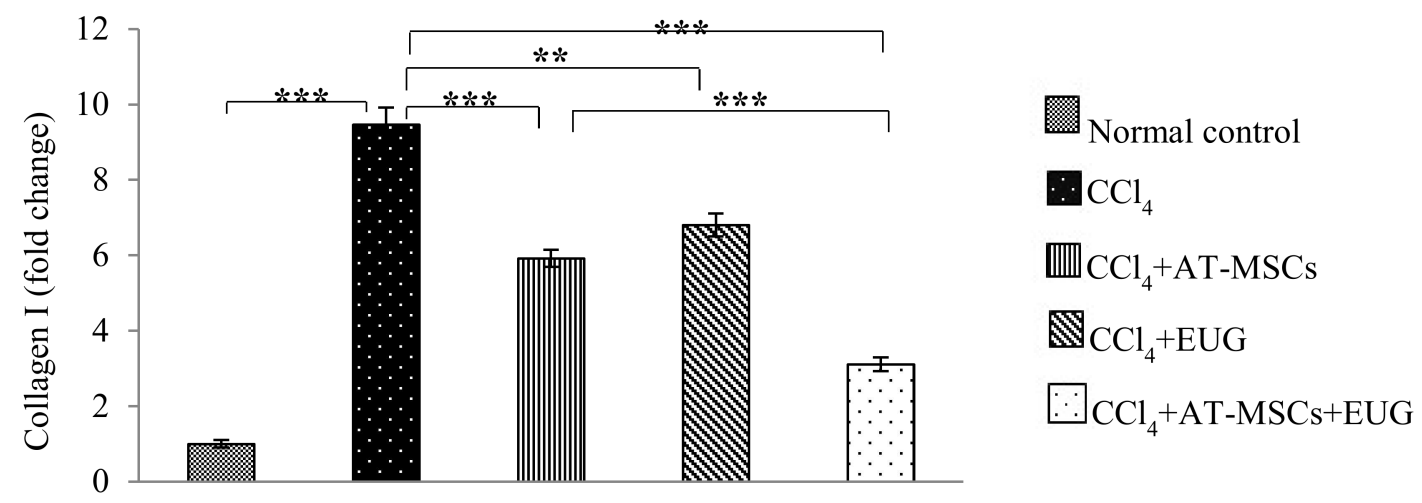

B

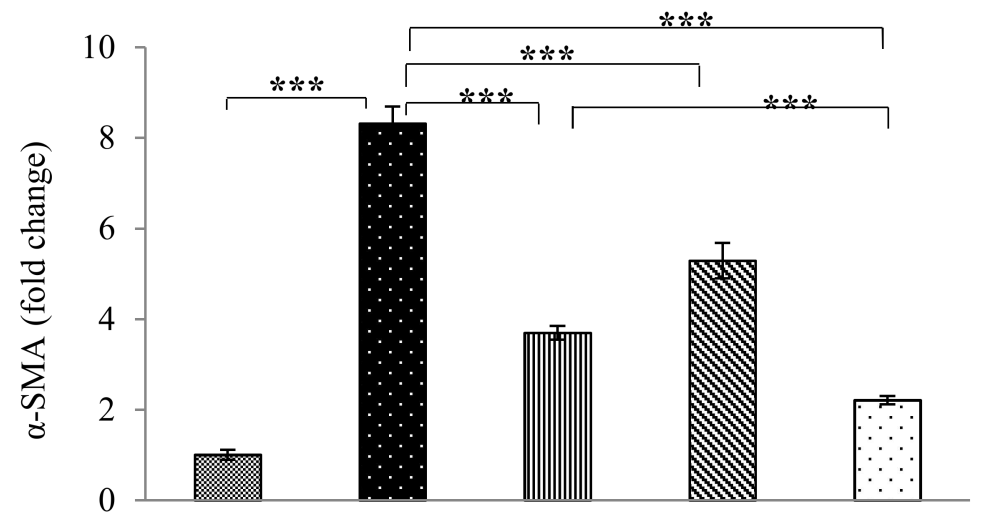

C

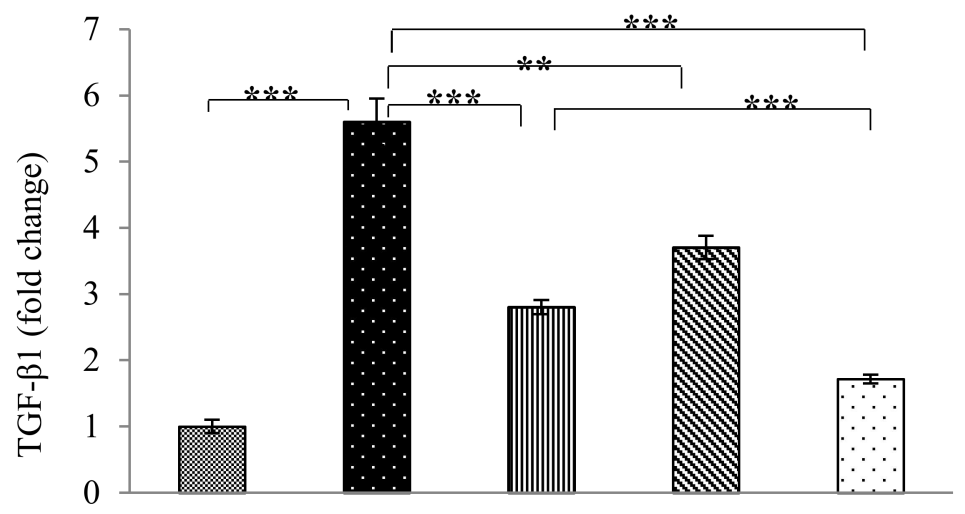

Figure 6. Expression of Type 1 collagen, $\alpha$-SMA and TGF- $\beta 1$ genes. Quantitative real time polymerase chain reaction (RT-PCR) was used to estimate the expression of (A) Type 1 collagen, (B) $\alpha$-SMA and (C) TGF- $\beta 1$ genes in hepatic tissues for the different groups. Fold change relative to the expression of normal control group and normalized to the internal control glyceraldehyde 3-phosphate dehydrogenase $(G A P D H)$ was shown. Bars represent mean \pm SD. Significant difference between groups is analyzed by one-way ANOVA test, where: ${ }^{* *} ; p<0.01$ and ${ }^{* * *} ; p<0.001$. AT-MSCs: Adipose tissue-derived mesenchymal stem cells, EUG: Eugenol, $\alpha$-SMA: $\alpha$-smooth muscle actin, TGF- $\beta 1$ : Transforming growth factor- $\beta, G A P D H$ : glyceraldehyde 3-phosphate dehydrogenase. 


\subsection{Expression of $\alpha$-SMA, TGF- $\beta 1$ and Phospho-Smad3 Proteins}

Hepatic expression of $\alpha$-SMA, TGF- $\beta 1$, Smad3 and phospho-Smad3 (P-Smad3) proteins was estimated by Western blot (Figure 7A). After normalization to $\beta$-actin protein expression and relative to that of the normal control group, the relative $\alpha$-SMA and TGF- $\beta 1$ proteins expression was $2.6 \pm 0.1$ and $2.8 \pm 0.1$ folds, respectively, in the $\mathrm{CCl}_{4}$ group, as shown in Figure $7 \mathrm{~B}$. Hepatic expression of both proteins was significantly decreased when rats were treated with AT-MSCs, EUG or both of them when compared to the $\mathrm{CCl}_{4}$ group. In addition, there is a significant $(p<0.001)$ difference between $\mathrm{CCl}_{4}+$ AT-MSCs and $\mathrm{CCl}_{4}+$ AT-MSCs + EUG groups.

A

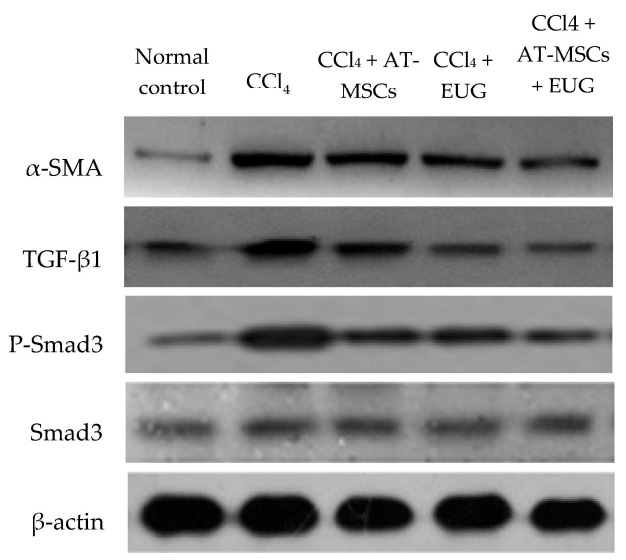

B

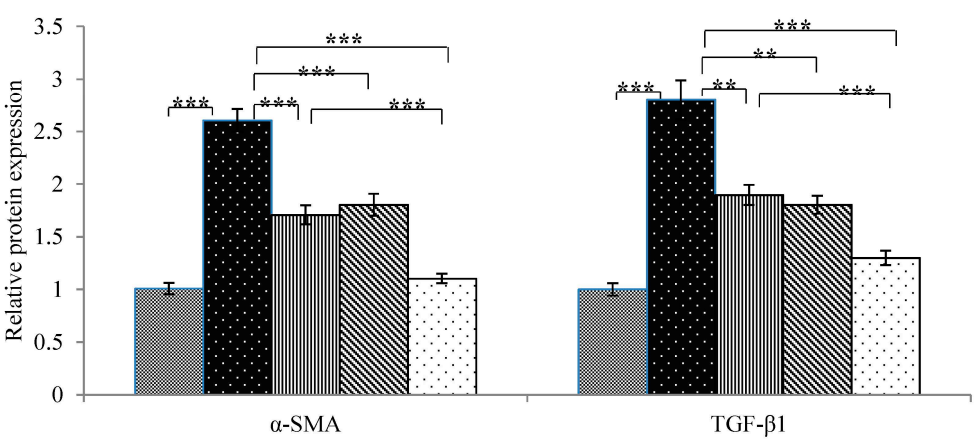

C

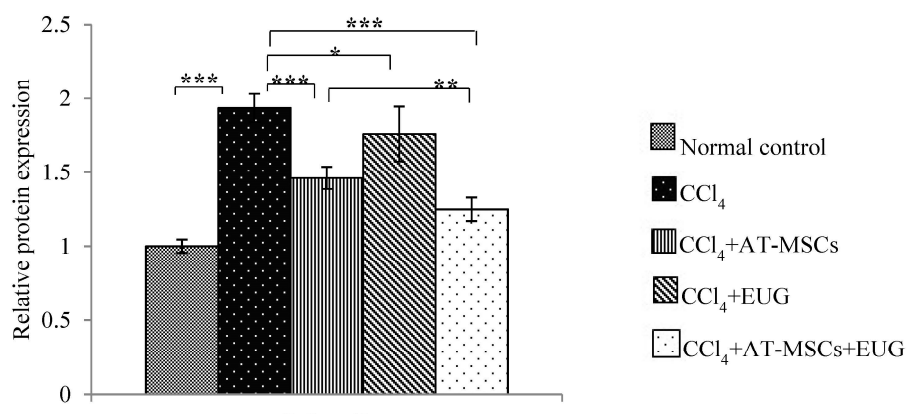

P-Smad3

Figure 7. Expression of $\alpha$-SMA, TGF- $\beta 1$ and phospho-Smad 3 proteins. (A) Representative immunoprecipitation blots of $\alpha$-SMA, TGF- $\beta 1$, Smad3 and P-Smad3 proteins for the different groups. (B) Relative expression of $\alpha$-SMA and TGF- $\beta 1$ proteins for the different groups, normalized to $\beta$-actin expression. (C) Relative expression of P-Smad3 protein for the different groups, normalized to $\beta$-actin and Smad3 proteins expression. Bars represent mean \pm SD. Significant difference between groups is analyzed by one-way ANOVA test, where: ${ }^{*} ; p<0.05,{ }^{* *} ; p<0.01,{ }^{* * *} ; p<0.001$. AT-MSCs: Adipose tissue-derived mesenchymal stem cells, EUG: Eugenol, $\alpha$-SMA: $\alpha$-smooth muscle actin, TGF- $\beta 1$ : Transforming growth factor- $\beta$. 
Figure 7C showed, after normalization to $\beta$-actin and Smad3 proteins expression, that P-Smad3 protein expression was significantly $(p<0.001)$ increased by $\mathrm{CCl}_{4}$ compared to the normal control group. Furthermore, the treatment with AT-MSCs, EUG or both of them significantly decrease its expression compared to the $\mathrm{CCl}_{4}$ group. Furthermore, there is a significant $(p<0.01)$ difference between $\mathrm{CCl}_{4}+$ AT-MSCs and $\mathrm{CCl}_{4}+$ AT-MSCs + EUG groups.

\subsection{Hepatic Histopathological Changes}

For normal control rats, hepatic histopathological investigation revealed no fatty changes or inflammatory infiltration and normal hepatic architecture. Hepatic sections of the $\mathrm{CCl}_{4}$ fibrotic group showed disarrangement of hepatocytes, fatty degeneration, necrosis and vacuole formation. Compared to $\mathrm{CCl}_{4}$ fibrotic rats, hepatic sections of rats treated with AT-MSCs or EUG showed enhanced changes, as the absence of vacuoles and necrosis, but moderate spaces between sinusoids were shown. In hepatic sections of rats treated with AT-MSCs and EUG, there is no obvious histological injury with reduced sinusoidal spaces and normal hepatocytes with distinct nuclei (Figure 8).

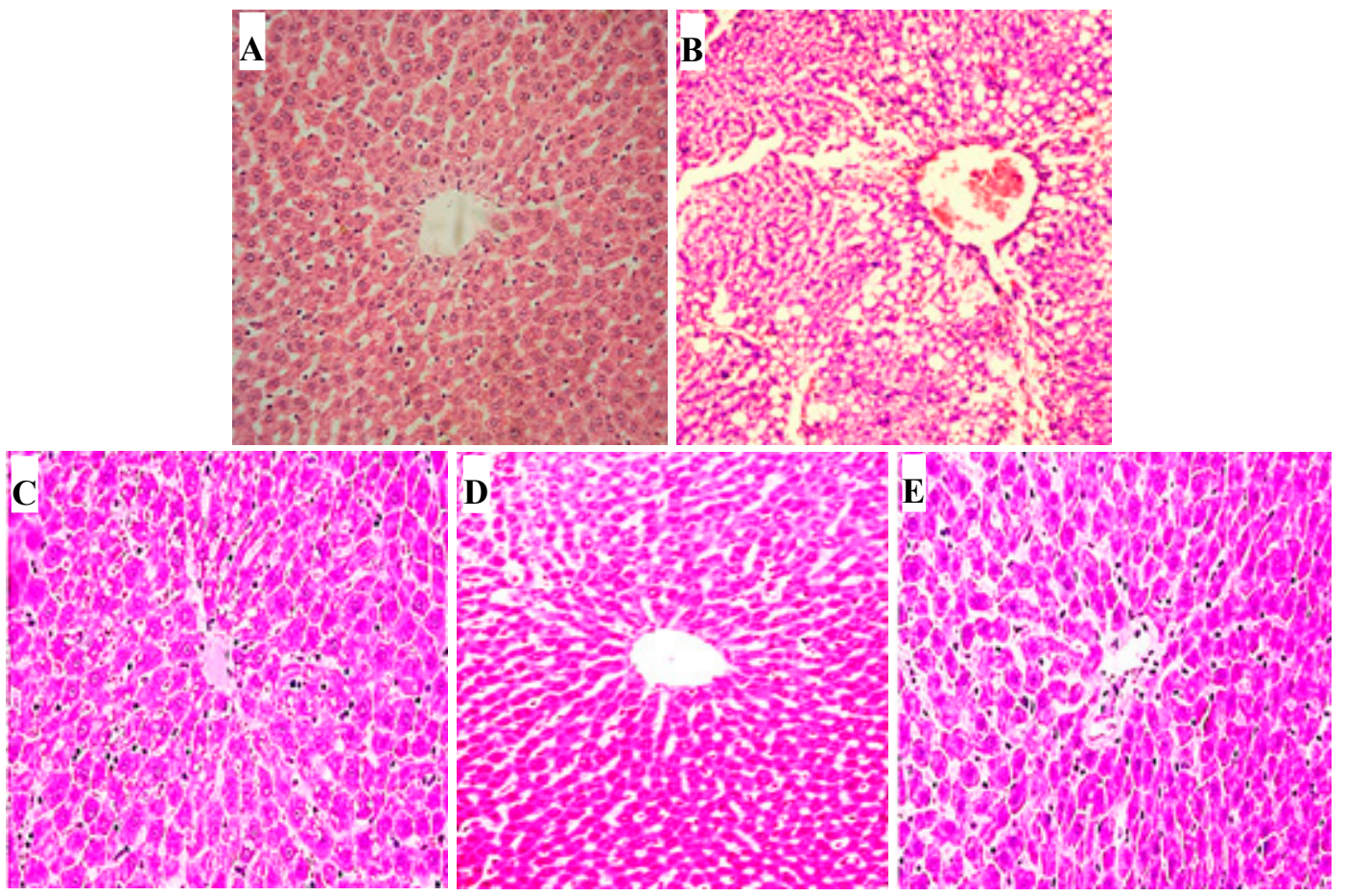

Figure 8. Histopathological examination for hepatic tissues. Hematoxylin-eosin (H\&E)-stained hepatic sections of: (A) normal control rats, (B) fibrotic rats which received $\mathrm{CCl}_{4},(\mathrm{C})$ rats receiving $\mathrm{CCl}_{4}$ + AT-MSCs, (D) rats who received $\mathrm{CCl}_{4}+\mathrm{EUG},(\mathrm{E})$ rats that received $\mathrm{CCl}_{4}+\mathrm{AT}-\mathrm{MSC}+\mathrm{EUG}$, (Magnification: $\times 100)$. AT-MSCs: Adipose tissue-derived mesenchymal stem cells, EUG: Eugenol.

\section{Discussion}

Recently, for treating hepatic disease, stem cell-based treatment has been suggested as an appropriate alternative strategy. During the past few years, researchers have reported that MSCs counter and exert therapeutic benefits against hepatic fibrosis [18,19]. Furthermore, the development of new approaches enhancing the MSCs therapy may be helpful to end-stage liver fibrosis patients.

It was reported that EUG exerted various pharmacological activities [20], and showed a hepatoprotective effect by improving the hepatic antioxidant capacity and declining the inflammation via the downregulation of the iNOS pathway [14]. Therefore, we hypothesized that treatment by AT-MSCs with EUG would yield an utmost antifibrotic effect and improvement in hepatic function compared with treatment with AT-MSCs alone. 
MSCs obtained from AT were characterized for the expression of surface markers by FCM. They highly expressed the MSCs markers (CD90, CD105 and CD73) and showed low expression of the hematopoietic markers (CD45 and CD34). In the present study, compared to the treatment with AT-MSCs alone, the combination treatment of the fibrotic rats with AT-MSCs and EUG significantly improved the plasma fibrinogen concentration, anti-inflammatory cytokine (IL-10) level and PCNA expression, and also significantly decreased the serum levels of liver enzymes (ALT and AST), inflammatory cytokines (TNF- $\alpha$, IL-1 $\beta$ and IL-6), fibrotic markers (type III collagen, hyaluronic acid, hydroxyproline) and the TGF- $\beta$ growth factor. Furthermore, the combination treatment also significantly decreased the hepatic expression of fibrotic markers genes (Type 1 collagen and $\alpha$-SMA) and proteins ( $\alpha$-SMA, TGF- $\beta 1$ and phospho-Smad3) more than the treatment with AT-MSCs alone.

Wound healing consists of many phases, including hemostasis, which involves blood coagulation. Blood coagulation ability could be measured by fibrinogen concentration and prothrombin time, which measures the blood coagulation extrinsic pathway [21]. In a hepatic fibrotic animal model, we have assessed the potential of the combination treatment with AT-MSCs and EUG on the hemostatic mechanism, for the first time, by attention to prothrombin time and fibrinogen concentration. This combination may enhance the hemostatic mechanism by stimulating the secretion of many growth factors and cytokines which help regulate hepatic cellular responses, stimulate the differentiation of endogenous tissue progenitors and the repair of hepatic tissues, and play an important role in hemostasis.

Fibrosis, in this study, was confirmed by measuring the liver enzymes level and a histopathology study. Hepatic tissues of fibrotic rats treated with AT-MSCs and EUG showed great improvements, compared with the fibrotic group, with the evanescence of necrosis and fatty changes which was near to the normal control hepatic sections. The combination treatment showed more antifibrotic effects than treatment with AT-MSCs alone, indicating the synergistic effects between AT-MSCs and EUG.

Hepatic damage, inflammation and fibrosis is always accompanied with elevated levels of hepatic enzymes and pro-inflammatory cytokines. The combination treatment of the fibrotic rats with AT-MSCs and EUG significantly reduced inflammatory reactions, diminished the levels of liver enzymes and the pro-inflammatory cytokines (TNF- $\alpha, \mathrm{Il}-1 \beta$, and Il-6), and increased the anti-inflammatory cytokine IL-10 level, reflecting the potent anti-inflammatory effect. Also, downregulation of the fibrotic genes (Type 1 collagen and $\alpha$-SMA) and the growth factor (TGF- $\beta 1$ ) expression, which was evaluated by quantitative RT-PCR, was significantly associated with the combination treatment more than that with the single treatment with AT-MSCs, indicating decreased hepatic fibrosis. Furthermore, the serum level of HGF was significantly increased, compared to the fibrotic group, only with the combination treatment, indicating repair of hepatic tissues and tissue remodeling.

Extracellular matrix (ECM) remodeling and collagen turnover are regulated by many matrix metalloproteinases (MMPs) and tissue inhibitors of metalloproteinases (TIMPs). During the process of fibrosis resolution, there is an increase in hepatic stellate cells apoptosis and collagenase activity; also there is a diminution in TIMP expression. It was reported that MSCs decreased TIMP-1 expression or increased the expression of MMPs in fibrotic models [22-24]. In this study, as well documented markers of fibrosis, levels of type III collagen, hyaluronic acid and hepatic hydroxyproline content, were estimated. Our results showed that levels of these fibrotic markers were significantly diminished, especially when the combination treatment was used. EUG might improve the antifibrotic effect of AT-MSCs by different mechanisms; it might increase the ability of AT-MSCs to suppress the pathological process initiated by inflammation, or increase AT-MSCs fusion with hepatocytes, which may contribute to microenvironment modification and differentiation into hepatocytes, leading to increased tissue regeneration and decreased fibrosis. Furthermore, EUG might increase the homing capacity of AT-MSCs for the injured liver, leading to more hepatocyte differentiation, resulting in increased hepatic PCNA expression in fibrotic rats treated with AT-MSCs and EUG, more than those treated with AT-MSCs alone. 
More interestingly, EUG, through its anti-inflammatory effect, might improve the immune-modulating activity of MSCs, which have the ability to increase the anti-inflammatory phenotype of macrophages, leading to increase the pro-regenerative factors levels.

Moreover, this study showed the hepatic up-regulation of $\alpha$-SMA and TGF- $\beta 1$ proteins and the phosphorylation of Smad3 protein in fibrotic rats. This upregulation was diminished by the combination treatment of AT-MSCs and EUG more than the single treatment with EUG. Actually, for hepatic fibrosis, the TGF- $\beta$ signaling pathway could be considered to be a promising therapeutic target. TGF- $\beta 1$, which is an important mediator for the progression of hepatic fibrosis, implements its fibrogenic functions, such as collagen synthesis, via the Smad pathway by the transmembrane TGF- $\beta$ receptors activation [25-27]. It was reported that the inhibition of TGF- $\beta 1$ suppressed the formation of 4-hydroxynonenal, which is a stable end product of lipid peroxidation and a factor of fibrotic processes, leading to mitotic activity restoration and the reduction of apoptosis in rat hepatocytes [28]. In this study, we found that, in fibrotic rats, AT-MSCs + EUG more strongly inhibited the TGF- $\beta / S m a d$ signaling pathway through the inhibition of Smad phosphorylation and the expression of TGF- $\beta 1$ and $\alpha$-SMA.

These data clearly showed the synergistic effect of EUG with AT-MSCs, which may represent a novel therapeutic approach for treating hepatic fibrosis, and in regenerative medicine. This approach is completely novel, to the best of our knowledge, so more investigations are necessary and currently going on, in order to enhance our understanding of the underlying molecular mechanisms accountable for the EUG effects on the antifibrotic potential of AT-MSCs, and to increase knowledge concerning the capability of our concept to be clinically viable.

\section{Materials and Methods}

\subsection{Drugs and Reagents}

All chemicals were purchased from commercial suppliers and were of analytical grade. Eugenol (99.0\%, Sigma Aldrich Company, St Louis, Missouri, USA) was prepared 1:1 (v/v) in olive oil at a concentration $10 \mathrm{mg} / \mathrm{mL}$, stored in the dark at $4{ }^{\circ} \mathrm{C}$ and equilibrated at room temperature before use. Carbon tetrachloride ( $\mathrm{CCl}_{4}$, Wako Pure Chemical Industries, Osaka, Japan) was diluted in olive oil $1: 1(v / v)$.

\subsection{Isolation, Culture and Characterization of AT-MSCS}

MSCs were obtained from the AT of two-month-old male rats (weighting $200 \pm 25 \mathrm{~g}$ ) using the method previously described by De Luna-Saldivar et al. [10]. The isolated AT-MSCs were cultured in Dulbecco's Modified Eagle's Medium (DMEM, Sigma-Aldrich, St. Louis, MO, USA) containing $10 \%$ fetal bovine serum (FBS, Biosolutions International, Melbourne, Australia) and 1\% Penicillin-Streptomycin mixture (Nacalai Tesque, Kyoto, Japan) at $37^{\circ} \mathrm{C}$ in a $5 \% \mathrm{CO}_{2}$ humidified incubator. The medium was changed every 3 days. Cells at $80 \%-85 \%$ confluence were trypsinized and passaged until the fourth passage. Then the cells were washed and suspended in PBS for use.

Characteristics of AT-MSCs were confirmed by FCM analysis to ensure that these cells express the MSC markers (CD73, CD105 and CD90), but not the hematopoietic markers (CD34 and CD45). Briefly, after blocking with 5\% bovine serum albumin (BSA; Sigma-Aldrich) in PBS for 30 min at room temperature, cells were stained at room temperature for $1 \mathrm{~h}$ with fluorescein isothiocyanate (FITC)or phycoerythrin (PE)-conjugated antibodies at a concentration of $20 \mu \mathrm{L} / 1 \times 10^{6}$ cells. Antibodies against CD90, CD105, CD34, CD45 (Beckman Coulter, Brea, CA, USA) and CD73 (BD Pharmingen, Franklin Lakes, NJ, USA) were used. Controls were incubated with FITC- or PE-conjugated same isotype control antibodies. The FACSCalibur flow cytometer (Becton Dickinson, Franklin Lakes, NJ, USA) was used for performing flow cytometry using Cell Quest software, and WinMDI ver 2.9 was used for data analysis. 


\subsection{Animals and the Experimental Design}

Fifty healthy male Crl: SD-1 (ICR) rats $(140 \pm 10 \mathrm{~g})$, purchased from Japan SLC (Hamamatsu, Japan), were used. Animal care and study protocols were preceded according to the guidelines established by The Experimental Animal Center and Research Ethics Committee, University of Toyama, Toyama, Japan. Hepatic fibrosis was induced by intraperitoneal (i.p.) injection of rats twice a week with $1 \mathrm{~mL} / \mathrm{kg} \mathrm{CCl}_{4}$ diluted in olive oil 1:1 (v/v) for six weeks [29]. AT-MSCs (9.75 million cells $/ \mathrm{kg}$ ), at week number three, intravenously (i.v.) injected, in $0.5 \mathrm{~mL}$ Plasma-Lyte A, into the tail vein of the rat slowly and cautiously to avoid an embolism [30]. Eugenol diluted in olive oil 1:1 (v/v) was intraperitonealy (i.p.) injected daily at a dose $10 \mathrm{mg} / \mathrm{kg}$ [14].

Rats were randomly divided into five groups:

Group 1 (normal control group): Rats injected only with olive oil.

Group 2 ( $\mathrm{CCl}_{4}$ group): Rats received $\mathrm{CCl}_{4}$ as described above.

Group $3\left(\mathrm{CCl}_{4}+\right.$ AT-MSCs group): Rats received $\mathrm{CCl}_{4}$ and a single dose of AT-MSCs at week 3 as described above.

Group $4\left(\mathrm{CCl}_{4}+\right.$ EUG group): Rats received $\mathrm{CCl}_{4}$ and EUG as described above.

Group $5\left(\mathrm{CCl}_{4}+\right.$ AT-MSCs + EUG group): Rats received $\mathrm{CCl}_{4}$, AT-MSCs and EUG as described above.

At the end of the experiment at week 7 , after fasting for $12 \mathrm{~h}$, the rats were anesthetized and blood samples were collected. Then, rats were sacrificed and liver samples were excised, washed and collected for analysis.

\subsection{Prothrombin Time and Fibrinogen Concentration Assay}

Using Coagpia ${ }^{\mathrm{TM}}$ PT-N kit (SEKISUI MEDICAL CO., LTD., Tokyo, Japan) according to manufacturer's instructions, prothrombin time was estimated. After blood collection in sodium citrate-containing centrifuge tubes, plasma was obtained after centrifugation. Briefly, to $100 \mu \mathrm{L}$ of plasma placed in a $37^{\circ} \mathrm{C}$ water bath, $200 \mu \mathrm{L}$ of thromboplastin reagent was added after pre-warming. Then, the time taken for clotting was calculated. Plasma fibrinogen concentration was estimated as described before [30].

\subsection{Assay of Serum Liver Enzymes, Inflammatory Cytokines and Growth Factors Levels}

Serum alanine transaminase (ALT) and aspartate transaminase (AST) enzyme activities were evaluated using commercially available kits purchased from Abcam KK, Tokyo, Japan according to the manufacturer's instructions. IL-6, IL-10, IL-1 $\beta$ and TNF- $\alpha$ cytokines were estimated by a Luminex analyzer (Merck, Darmstadt, Germany). The levels of growth factors, HGF and TGF- $\beta$, were estimated with enzyme-linked immunosorbent assay (ELISA) kits (Abcam KK) using HTS Multi-Mode Microplate Reader (BioTek Instruments, Winooski, VT, USA) according to the manufacturer's instruction.

\subsection{Measurement of Serum Levels of Type III Collagen and Hyaluronic Acid and Hepatic Hydroxyproline Content}

ELISA kits were used for the determination of serum levels of type III collagen (LifeSpan BioSciences, Inc., Seattle, WA, USA) and hyaluronic acid (AMS Biotechnology Ltd., Abingdon, UK) according to the manufacturer's instructions.

For measurement of hepatic hydroxyproline content, hepatic tissues were hydrolyzed at $120^{\circ} \mathrm{C}$ for $16 \mathrm{~h}$ with $6 \mathrm{~N} \mathrm{HCl}$. The lysates were cooled and centrifuged for $10 \mathrm{~min}$ at 13,000× $\mathrm{g}$ after neutralization with $6 \mathrm{~N} \mathrm{NaOH}$. Acetate/citrate buffer and $7 \%$ chloramine T were added to the supernatants. Then, the mixture was incubated at $60{ }^{\circ} \mathrm{C}$ for $35 \mathrm{~min}$ with Ehrlich's solution. The absorbance was measured, after cooling, at $560 \mathrm{~nm}$ using HTS Multi-Mode Microplate Reader (BioTek Instruments). For each sample, the hydroxyproline concentration was calculated from the standard curve, prepared by 
hydroxyproline (Sigma Aldrich, St. Louis, MO, USA). Concentration was expressed as micrograms per gram of hepatic tissue.

\subsection{Proliferating Cell Nuclear Antigen Expression Determination}

For immunohistochemistry, hepatic paraffin-sections were stained with anti-PCNA antibody (1:4000) (Abcam), according to the manufacturer's instructions, using the Horseradish peroxidase/DAB (ABC) detection immunohistochemistry kit (Abcam, Cambridge, UK). As shown in Table 1, immuno-reactive score (IRS) was obtained by the product of the intensity of staining score (0-3) and the percentage of positive cells score (0-4) [31].

Table 1. The immunoreactive score (IRS) calculation (IRS: $\mathrm{A} \times \mathrm{B}=0-12$ ).

\begin{tabular}{ccc}
\hline A (Percentage of Positive Cells) & B (Intensity of Staining) & IRS Score $(\mathbf{A} \times \mathbf{B})$ \\
\hline $0=$ no positive cells & $0=$ no color reaction & $0-1=$ negative \\
$1=<10 \%$ of positive cells & $1=$ mild reaction & $2-3=$ mild \\
$2=10 \%-50 \%$ positive cells & $2=$ moderate reaction & $4-8=$ moderate \\
$3=51 \%-80 \%$ positive cells & $3=$ intense reaction & $9-12=$ strongly positive \\
$4=>80 \%$ positive cells & & \\
\hline
\end{tabular}

\subsection{Quantitative Real-Time Polymerase Chain Reaction}

Total RNA was isolated from hepatic tissue using Isogen (Nippon Gene, Tokyo, Japan) according to the manufacturer's protocol. After treatment with deoxyribonuclease I (DNase I, Sigma-Aldrich, Inc,), cDNA was formed using $1 \mu \mathrm{g}$ total RNA by the PrimeScript ${ }^{\mathrm{TM}}$ RT reagent kit (Takara Bio, Kusatsu, Japan) with oligo-dT (Applied Biosystems, Foster City, CA, USA). Transcript levels were measured by real-time PCR using the sequence-specific primers, shown in Table 2. Amplification was performed in an ABI PRISM 7900HT Sequence Detector (Applied Biosystems, Foster City, CA, USA) using SYBR Green PCR Master Mix (Applied Biosystems) according to the manufacturer's instructions. Glyceraldehyde 3-phosphate dehydrogenase (GAPDH) was used as internal control gene. Gene expression levels were determined using the comparative threshold cycle $(\Delta \Delta \mathrm{C} t)$ method after normalization to GAPDH as a housekeeping gene.

Table 2. Primers used in quantitative real-time polymerase chain reaction (PCR) assay.

\begin{tabular}{|c|c|}
\hline Primer & Sequence of the Primer \\
\hline \multirow{2}{*}{ type 1 collagen } & Forward: 5'-CAT GTT CAG CTT TGT GGA CCT-3' \\
\hline & Reverse: 5'-GCA GCT GAC TTC AGG GAT GT-3'. \\
\hline \multirow{2}{*}{$\alpha-S M A$} & Forward: 5'-CGA TAG AAC ACG GCA TCA TCA C-3' \\
\hline & Reverse: 5'-GCA TAG CCC TCA TAG ATA GGC A-3'. \\
\hline \multirow{2}{*}{$T G F-\beta 1$} & Forward: 5'-GGA CTC TCC ACC TGC AAG AC-3' \\
\hline & Reverse: 5'-GAC TGG CGA GCC TTA GTT TG-3'. \\
\hline \multirow{2}{*}{$G A P D H$} & Forward: 5'-AGA CAG CCG CAT CTT CTT GT-3' \\
\hline & Reverse: 5'-TGA TGG CAA CAA TGT CCA CT-3'. \\
\hline
\end{tabular}

\subsection{Western Blotting Analysis for Hepatic $\alpha$-SMA, TGF- $\beta 1$, Smad3 and Phospho-Smad3 Proteins Expression}

Parts of the hepatic tissues were homogenized in T-PER protein extraction reagent (Thermo Fisher Scientific Life Sciences, Waltham, MA, USA) using a Tissue Lyser II apparatus (Qiagen GmbH, Haan, Germany). The homogenates were centrifuged and, using a protein assay kit (Bio-Rad Laboratories Inc., Hercules, CA, USA), the protein concentrations of the supernatants were estimated. A total protein of $50 \mu \mathrm{g}$ of each homogenate was transferred to a polyvinylidene difluoride (PVDF) membrane (EMD Millipore, Billerica, MA, USA), after electrophoresis on a $12 \%$ sodium dodecyl sulfate-polyacrylamide (SDS-PAGE) gel. After blocking in a Tris-buffered saline (TBS-T) blocking solution containing $0.05 \%$ 
Tween-20 and 5\% $(w / v)$ non-fat milk for $1 \mathrm{~h}$, membranes were incubated overnight with primary antibodies for $\alpha$-SMA (42 kDa), TGF- $\beta 1$ (28 kDa), Smad3 (52 kDa), phospho-Smad3 (55 kDa) (Abcam, 1:1000) and $\beta$-actin (42 kDa, Santa Cruz Biotechnology, Santa Cruz, CA, USA) at $4{ }^{\circ} \mathrm{C}$. After washing, membranes were incubated for $1 \mathrm{~h}$ at room temperature with horseradish peroxidase-conjugated polyclonal goat anti-rabbit immunoglobulin secondary antibody (Cell Signaling Technology, Danvers, MA, USA). Band visualization was done using an enhanced chemiluminescence detection kit (GE Healthcare, Chicago, IL, USA) according to the manufacturer's instructions and detected by the image analyzer for luminescent (LAS-4000, Fujifilm Co., Tokyo, Japan). The band intensity was assessed densitometrically, relative to that of the normal control group after normalization to $\beta$-actin.

\subsection{Histopathological Examination}

After formalin fixation, hepatic sections were dehydrated in ascending grades of ethanol and embedded in paraffin. Then, the sections were stained with hematoxylin and eosin $(H \& E)$ and observed for histopathological changes using the light electric microscope (Leika DMRBE, Biberach, Germany) using the DPController software.

\subsection{Statistical Analysis}

Using Statistical Package for the Social Sciences (SPSS version 16.0, IBM, Chicago, IL, USA), data were analyzed by one-way analysis of variance (ANOVA), followed by post hoc Tukey's test, and expressed as mean \pm standard deviation. $p<0.05$ was considered statistically significant.

\section{Conclusions}

In conclusion, these results elucidate that the combination treatment with EUG and AT-MSCs, in rats, strongly inhibited the advancement of $\mathrm{CCl}_{4}$-induced hepatic fibrosis, compared with AT-MSCs alone. Therefore, the future use of this combination could exert an efficient and novel therapeutic strategy for patients with hepatic fibrosis. Future clinical studies and increasing the knowledge for the therapeutic mechanisms are required to increase our perception of the effects of EUG on the antifibrotic potential of AT-MSCs.

Author Contributions: Conceptualization, M.F., T.Y. and M.O.; Methodology and Investigation, M.F. and M.O.; Validation, M.O., H.M.S.E.; Formal Analysis, M.F., H.M.S.E.; Resources, T.Y. and H.M.S.E.; Data curation, H.M.S.E., M.F. and T.Y.; Writing_-Original Draft Preparation, M.F. and M.O.; Writing-Review \& Editing, H.M.S.E. and T.Y.; Visualization, M.F., T.Y. All authors have read and agreed to the published version of the manuscript.

Funding: This research received no external funding.

Conflicts of Interest: The authors declare no conflict of interest.

\section{References}

1. Koike, C.; Zhou, K.; Takeda, Y.; Fathy, M.; Okabe, M.; Yoshida, T.; Nakamura, Y.; Kato, Y.; Nikaido, T. Characterization of amniotic stem cells. Cell. Reprogram. 2014, 16, 298-305. [CrossRef] [PubMed]

2. Nagura, S.; Otaka, S.; Koike, C.; Okabe, M.; Yoshida, T.; Fathy, M.; Fukahara, K.; Yoshimura, N.; Misaki, T.; Nikaido, T. Effect of exogenous Oct4 overexpression on cardiomyocyte differentiation of human amniotic mesenchymal cells. Cell. Reprogram. 2013, 15, 471-480. [CrossRef] [PubMed]

3. Otaka, S.; Nagura, S.; Koike, C.; Okabe, M.; Yoshida, T.; Fathy, M.; Yanagi, K.; Misaki, T.; Nikaido, T. Selective isolation of nanog-positive human amniotic mesenchymal cells and differentiation into cardiomyocytes. Cell. Reprogram. 2013, 15, 80-91. [CrossRef] [PubMed]

4. Parekkadan, B.; Milwid, J.M. Mesenchymal stem cells as therapeutics. Annu. Rev. Biomed. Eng. 2010, 12, 87-117. [CrossRef]

5. Li, Q.; Zhou, X.; Shi, Y.; Li, J.; Zheng, L.; Cui, L.; Zhang, J.; Wang, L.; Han, Z.; Han, Y.; et al. In vivo tracking and comparison of the therapeutic effects of MSCs and HSCs for liver injury. PLoS ONE 2013, 8, e62363. [CrossRef] 
6. Jang, Y.O.; Cho, M.Y.; Yun, C.O.; Baik, S.K.; Park, K.S.; Cha, S.K.; Chang, S.J.; Kim, M.Y.; Lim, Y.L.; Kwon, S.O. Effect of Function-Enhanced Mesenchymal Stem Cells Infected with Decorin-Expressing Adenovirus on Hepatic Fibrosis. Stem Cells Transl. Med. 2016, 5, 1247-1256. [CrossRef]

7. Kern, S.; Eichler, H.; Stoeve, J.; Kluter, H.; Bieback, K. Comparative analysis of mesenchymal stem cells from bone marrow, umbilical cord blood, or adipose tissue. Stem Cells 2006, 24, 1294-1301. [CrossRef]

8. Lotfy, A.; Salama, M.; Zahran, F.; Jones, E.; Badawy, A.; Sobh, M. Characterization of mesenchymal stem cells derived from rat bone marrow and adipose tissue: A comparative study. Int. J. Stem Cells 2014, 7, 135-142. [CrossRef]

9. Terai, S.; Ishikawa, T.; Omori, K.; Aoyama, K.; Marumoto, Y.; Urata, Y.; Yokoyama, Y.; Uchida, K.; Yamasaki, T.; Fujii, Y.; et al. Improved liver function in patients with liver cirrhosis after autologous bone marrow cell infusion therapy. Stem Cells 2006, 24, 2292-2298. [CrossRef]

10. De Luna-Saldivar, M.M.; Marino-Martinez, I.A.; Franco-Molina, M.A.; Rivera-Morales, L.G.; Alarcon-Galvan, G.; Cordero-Perez, P.; Rojas-Martinez, A.; Rodriguez-Padilla, C.; Munoz-Espinosa, L.E. Advantages of adipose tissue stem cells over CD34(+) mobilization to decrease hepatic fibrosis in Wistar rats. Ann. Hepatol. 2019, 18, 620-626. [CrossRef]

11. Bataller, R.; Brenner, D.A. Liver fibrosis. J. Clin. Investig. 2005, 115, 209-218. [CrossRef] [PubMed]

12. Friedman, S.L. Hepatic stellate cells: Protean, multifunctional, and enigmatic cells of the liver. Physiol. Rev. 2008, 88, 125-172. [CrossRef] [PubMed]

13. Wang, J.; Cen, P.; Chen, J.; Fan, L.; Li, J.; Cao, H.; Li, L. Role of mesenchymal stem cells, their derived factors, and extracellular vesicles in liver failure. Stem Cell Res. 2017, 8, 137. [CrossRef] [PubMed]

14. Fathy, M.; Khalifa, E.; Fawzy, M.A. Modulation of inducible nitric oxide synthase pathway by eugenol and telmisartan in carbon tetrachloride-induced liver injury in rats. Life Sci. 2019, 216, 207-214. [CrossRef] [PubMed]

15. Saad Eldien, H.M.; Abdel-Aziz, H.O.; Sayed, D.; Mubarak, W.; Hareedy, H.H.G.; Mansor, S.G.; Yoshida, T.; Fathy, M. Periostin expression and characters of human adipose tissue-derived mesenchymal stromal cells were aberrantly affected by in vitro cultivation. Stem Cell Investig. 2019, 6, 33. [CrossRef]

16. Higuchi, O.; Okabe, M.; Yoshida, T.; Fathy, M.; Saito, S.; Miyawaki, T.; Nikaido, T. Stemness of human Wharton's jelly mesenchymal cells is maintained by floating cultivation. Cell. Reprogram. 2012, 14, 448-455. [CrossRef]

17. Zhou, K.; Koike, C.; Yoshida, T.; Okabe, M.; Fathy, M.; Kyo, S.; Kiyono, T.; Saito, S.; Nikaido, T. Establishment and characterization of immortalized human amniotic epithelial cells. Cell. Reprogram. 2013, 15, 55-67. [CrossRef]

18. Kharaziha, P.; Hellstrom, P.M.; Noorinayer, B.; Farzaneh, F.; Aghajani, K.; Jafari, F.; Telkabadi, M.; Atashi, A.; Honardoost, M.; Zali, M.R.; et al. Improvement of liver function in liver cirrhosis patients after autologous mesenchymal stem cell injection: A phase I-II clinical trial. Eur. J. Gastroenterol. Hepatol. 2009, 21, 1199-1205. [CrossRef]

19. Kim, G.; Eom, Y.W.; Baik, S.K.; Shin, Y.; Lim, Y.L.; Kim, M.Y.; Kwon, S.O.; Chang, S.J. Therapeutic Effects of Mesenchymal Stem Cells for Patients with Chronic Liver Diseases: Systematic Review and Meta-analysis. J. Korean Med. Sci. 2015, 30, 1405-1415. [CrossRef]

20. Fathy, M.; Fawzy, M.A.; Hintzsche, H.; Nikaido, T.; Dandekar, T.; Othman, E.M. Eugenol Exerts Apoptotic Effect and Modulates the Sensitivity of HeLa Cells to Cisplatin and Radiation. Molecules 2019, $24,3979$. [CrossRef]

21. Ryeom, H.K.; Kim, S.H.; Kim, J.Y.; Kim, H.J.; Lee, J.M.; Chang, Y.M.; Kim, Y.S.; Kang, D.S. Quantitative evaluation of liver function with MRI Using Gd-EOB-DTPA. Korean J. Radiol. 2004, 5, 231-239. [CrossRef] [PubMed]

22. Ali, G.; Mohsin, S.; Khan, M.; Nasir, G.A.; Shams, S.; Khan, S.N.; Riazuddin, S. Nitric oxide augments mesenchymal stem cell ability to repair liver fibrosis. J. Transl. Med. 2012, 10, 75. [CrossRef] [PubMed]

23. Liu, C.H.; Hwang, S.M. Cytokine interactions in mesenchymal stem cells from cord blood. Cytokine 2005, 32, 270-279. [CrossRef] [PubMed]

24. Wu, Y.; Huang, S.; Enhe, J.; Ma, K.; Yang, S.; Sun, T.; Fu, X. Bone marrow-derived mesenchymal stem cell attenuates skin fibrosis development in mice. Int. Wound J. 2014, 11, 701-710. [CrossRef]

25. Dooley, S.; ten Dijke, P. TGF-beta in progression of liver disease. Cell Tissue Res. 2012, 347, 245-256. [CrossRef] 
26. Inagaki, Y.; Higashiyama, R.; Higashi, K. Novel antifibrotic modalities for liver fibrosis: Molecular targeting and regenerative medicine in fibrosis therapy. J. Gastroenterol. Hepatol. 2012, 27 (Suppl. 2), 85-88. [CrossRef]

27. Rosenbloom, J.; Mendoza, F.A.; Jimenez, S.A. Strategies for antifibrotic therapies. Biochim. Biophys. Acta 2013, 1832, 1088-1103. [CrossRef] [PubMed]

28. Albright, C.D.; Borgman, C.; Craciunescu, C.N. Activation of a caspase-dependent oxidative damage response mediates TGFbeta1 apoptosis in rat hepatocytes. Exp. Mol. Pathol. 2003, 74, 256-261. [CrossRef]

29. Wang, G.; Li, Z.; Li, H.; Li, L.; Li, J.; Yu, C. Metabolic Profile Changes of CCl(4)-Liver Fibrosis and Inhibitory Effects of Jiaqi Ganxian Granule. Molecules 2016, 21, 698. [CrossRef]

30. Aithal, A.P.; Bairy, L.K.; Seetharam, R.N.; Kumar, N. Hemostatic potential of human bone marrow-derived mesenchymal stromal cells in Wistar rats with carbon tetrachloride induced liver cirrhosis. Stem. Cell. Investig. 2018, 5, 21. [CrossRef] [PubMed]

31. Remmele, W.; Stegner, H.E. Recommendation for uniform definition of an immunoreactive score (IRS) for immunohistochemical estrogen receptor detection (ER-ICA) in breast cancer tissue. Pathologe 1987, 8, 138-140. [PubMed]

Sample Availability: Samples of the compounds are not available from the authors.

(C) 2020 by the authors. Licensee MDPI, Basel, Switzerland. This article is an open access article distributed under the terms and conditions of the Creative Commons Attribution (CC BY) license (http://creativecommons.org/licenses/by/4.0/). 